UDC 621.391

DOI: 10.15587/2706-5448.2021.229440

Article type «Reports on Research Projects»

\section{Andrii Shyshatskyi, \\ Vitalii Hasan, \\ Mykola Kryvenko, \\ Oleksandr Petrov, \\ Serhii Kravchuk, \\ Yuriy Shidlovsky, \\ Andrii Opalak, \\ Oleksandr Modlinskyi, \\ Oleksii Kobylynskyi, \\ Ihor Bezstrochnyi}

\title{
JUSTIFICATION OF WAYS INCREASING THE IMMUNITY OF SPECIAL PURPOSE RADIO COMMUNICATIONS
}

The object of research is the military radio communication system. One of the most problematic areas in the military radio resources management is the interference of military radio systems and facilities. A number of works have been devoted to the study of ways to increase the noise immunity of military radio communication systems and facilities. However, the known works contain some research results by scientists, which are aimed at increasing the noise immunity of military radio communication systems and devices and do not have a comprehensive approach. This work solves the problem of substantiating ways to increase the noise immunity of military radio communication systems and facilities.

The scientific problem is solved by substantiating the methodological principles of increasing the noise immunity of military radio communication systems in conditions of a priori uncertainty. During the research, the authors used the main provisions of the queuing theory, the theory of automation, the theory of complex technical systems, as well as general scientific methods of cognition, namely analysis and synthesis. The novelty is that in the course of work:

- the purpose of functioning of the noise protection system of military radio communication systems is formulated;

- indicators and criteria for increasing the noise immunity of military radio communication systems have been determined;

- decomposition of the solution of this problem into problems depending on the signal and noise situation is carried out.

An approach based on the hierarchical decomposition of the networks functional structure, the behavior of which is described by stochastic differential (or difference) equations of the high dimension state, into a number of interconnected but simpler functional structures is used for the functional description of military radio communication systems. The proposed approach to describe the behavior of military radio systems will allow to decompose the military radio system state and increase the efficiency of decision-making to adjust operating modes and parameters in real time. The results of the research should be used at the stage of parameters operational management and modes of the system operation.

Keywords: military radio communication system, hierarchical decomposition, functional structure of networks, electronic suppression, destabilizing factors.

Shyshatskyi, A., Hasan, V., Kryvenko, M., Petrov, O., Kravchuk, S., Shidlovsky, Y., Opalak, A., Modlinskyi, O., Kobylynskyi, O., Bezstrochnyi, I. (2021). Justification of ways increasing the immunity of special purpose radio communications. Technology Audit and Production Reserves, 2 (2 (58)), 46-50. doi: http://doi.org/10.15587/2706-5448.2021.229440

\section{Introduction}

According to the experience of local wars and armed conflicts in recent decades, during operations (combat operations), radio communication systems are usually the basis of any military weapon control system, as well as communication and information transmission systems. It happens because of the high dynamics of hostilities, long range and the ability to work in motion [1,2].
Taking into consideration the great importance of military radio communication systems in the management and communication system of troops (forces) group, there is a need to find new ways to increase their effectiveness. It should be noted that in modern military conflicts, radio communication systems are used to meet the needs of troops (forces) mobile groups.

As it is known, the military communication radio system consists of a stationary and a field component (mobile 
component). At the same time, the stationary component of the military radio communication system is the primary target of high-precision devices. That is why the stationary component of the military radio communication system is designed for the deployment of the field component (mobile component). Peculiarities of combat use of the mobile component (MC) of military radio communication systems (MRCS) involve the creation of a control system characterized by adaptability, reliability, and a given quality of operation in conditions of a priori uncertainty about the communication system state [3, 4].

The MRCS state is influenced by a large number of conditions and factors that determine the conditions of MRCS combat use and individual elements of MRCS. Particular attention should be paid to the fact that the combat use of MRCS takes place in conditions of scarcity of various resources allocated for the organization of radio communication systems, as well as in the conditions of the electronic warfare use by the enemy. Taking into consideration the above, the topical issue is the search for new ways to increase the noise immunity of radio communication systems, operating under the influence of electronic warfare and shortage of radio resources. It will ensure the required quality of radio communication information exchange at the minimum necessary cost of all MRCS resources.

Thus, the object of research is the military radio system. And the aim of research should be considered to increase the efficiency of the military radio system by substantiating the new principles of increasing noise immunity.

\section{Methods of research}

The analysis of scientific works [1,2,5], which investigated the analysis of MRCS noise immunity, is limited only by the research of the intentional interference impact on MRCS noise protection, described by the normal Gaussian distribution law. In this case, let's consider only additive nature intentional interferences, without taking into account the multiplicative interferences and interferences described by the non-Gaussian distribution law.

Signal fading is usually described only by the law of Rayleigh, Rice and Nakagami. Moreover, in the known works, the authors to simplify the calculations calculate the fading effect only in accordance with Rice's law.

The noise immunity of radio channels is significantly impaired when the signal is faded, because it is not possible to use information about the actual values of the radio signals parameters. Thus, random changes in the transmission channel parameters are the multiplicative interferences, which leads to distortion of the transmitted signals in the form of random parameters changes [1, 2, 6].
During the research, the authors used the main provisions of queuing theory, automation theory, theory of complex technical systems, information transfer theory, theory of signal-code constructions and general scientific cognition methods, namely analysis and synthesis.

\section{Research results and discussion}

Let's consider the destabilizing factors that affect the noise immunity of the military radio system. The main destabilizing factors are: intentional plants, signal replacement, Doppler effect and natural interference.

Fig. 1 shows the classification of intentional and natural interference, which is used to disrupt the functioning of the system and devices of military radio communication systems and provide information during the transmission process.

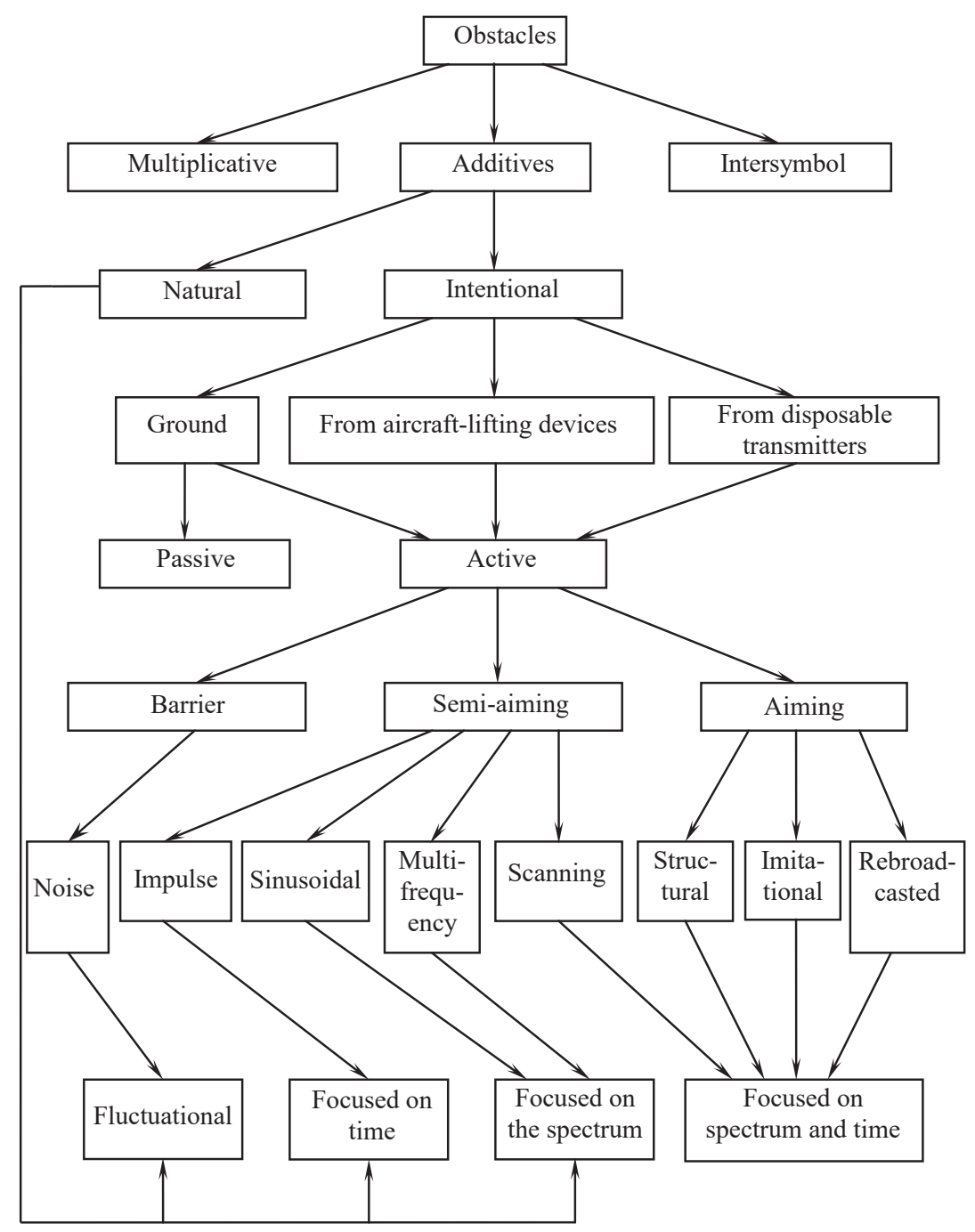

Fig. 1. General classification of intentional and natural interference

The probability of erroneous signal reception at the input allows to obtain a description for the expression [5]:

$$
P_{\text {errori }}=\frac{1}{2}\left[1-\Phi\left(\sqrt{\frac{2 E_{b i}}{G_{0 i}}}\right)\right],
$$

where $E_{b i}$ is the received bit energy of the useful signal information; $G_{0 i}$ is the noise spectral power density 
( $G_{0 i}=P_{n} / F_{s}$, where $P_{n}$ is the interference (noise) power; $F_{s}$ is the signal frequency band);

$$
\Phi(x)=\frac{2}{\sqrt{2 \pi}} \int_{0}^{x} e\left(-\frac{t^{2}}{2}\right) \mathrm{d} t
$$

is the Cramp function. Obstacle $b(t)$ (some obstacles $b_{1}(t)$, $\left.b_{2}(t), \ldots, b_{n}(t)\right)$, affecting the transmitted (useful signal) $A(t)$ of the radio channel can be described by the operator $[2,5]$ :

$$
Z(t)=V(A(t), b(t))
$$

where $Z(t)$ is the signal at the receiver input; $b(t)$ is the interference effect on the useful signal.

If this operator can be written as the sum of the useful signal, then $b_{a}(t)$ in (3) has an additive nature of the effect on the received signal:

$$
Z(t)=A(t)+b(t)
$$

The interference that causes changes in the useful signal parameters of nonlinear character $A(t)$ is called multiplicative and described by the following expression:

$$
Z(t)=A(t) \cdot b(t)
$$

As a rule, intentional interference created by electronic suppression interact devices with the useful signal in accordance with expression (3).

Symbolic interference appears because modern military radio communication systems have been dramatically increased in terms of the information transmission speed. At the same time, it is necessary to increase the speed of information transmission with a limited frequency band of military radio transmitters. The specified bandwidth radio channel distorts the transmitted useful signal, which leads to stretching of the signals in the time plane and, in turn, to the overlap of useful signals on each other. Intersymbol interferences are described by both multiplicative and additive law.

With the simultaneous influence of additive and multiplicative interference on the useful signal, the distorted signal at the input of the demodulator is described by the following expression:

$$
Z(t)=b_{m}(t) \cdot A(t)+b_{a}(t) .
$$

By origin, obstacles are divided into intentional and unintentional. Intentional obstructions are created by specially created interference set-ups installed at different transport bases.

Active intentional interference by spectral-temporal characteristics is divided into sighting, semi-aiming and blocking [2,6].

Blocking active intentional interference is realized in a specific band of operating frequencies of the radio receiver, which leads to distortions of the transmitted information signals in the frequency and time planes. The most common are continuous noise barriers, which cover the entire operating frequency range of radio communication systems. Noise interference from electronic warfare devices is usually described by the Gaussian distribution law, so the interference power density is evenly distributed over the entire spectrum of the interference signal. Technically, this type of interference is quite simple, so this type of interference has been actively used since the middle of the last century in the main radioelectronic warfare devices.

The semi-targeted active intentional interference only partially coincides with the frequency-time characteristics of the suppressed radio signal.

Targeted active intentional interference occupies exactly the same operating frequency band as the spectrum of the useful radio signal, and its effect coincides with the time of information transmission. Target interference is the most destructive in terms of information reception noise immunity.

The research results on the noise immunity of information transmission in radio communication systems $[5,7,8]$ indicate that additive interference can be divided into three main classes: fluctuation, pulse (time-focused) and narrowband (spectrum-focused).

Fluctuation is a constant chaotic process that can be represented as the sum of the oscillations caused by the instability of the radio element base of the radio communication devices. This type of interference creates the greatest destructive effect on the useful signal for the following reasons:

- fluctuation noise is always in the radio channel;

- fluctuation noise completely occupies the band of the useful signal in time and frequency range;

- fluctuation noise has good approximating properties from other sources of noise.

A pulse noise is a sequence of pulses of short duration that occur as a result of short-term electromagnetic oscillations. These pulses are much shorter in duration than the signal duration, and the bandwidth of the pulse noise is much larger than the bandwidth of the useful signal $\left(\Delta t_{\zeta} \gg \tau_{c}, \Delta f_{\zeta} \gg \Delta f_{c}\right)$.

Impulse noise per unit time is described according to a law close to Poisson's law:

$$
p(n)=\frac{n_{0}^{n} e^{-n_{0}}}{n !},
$$

where $n_{0}$ is the number of pulses over a period of time.

Narrowband is a type of interference that is described in the form of oscillations, the parameters of which change slowly or are constant in the duration of the useful signal.

The effect of narrowband interference on the reception of the signal at the input of the radio receiver can be classified as follows:

- interference is concentrated in the frequency band of the useful signal, which completely or partially coincides with the frequency band of the useful signal; - interference, the spectrum of which is outside the frequency band of the useful signal, or in the operating frequency range of the radio receiver;

- interference, the spectrum of which is outside the operating range of the radio receiver, but in nonlinear transformations components get into at the input of the radio receiver operating range.

The operation of military radio systems involves the presence of different copies numbers of the useful signal at the receiver input, which came to the input of the receiver in different ways. This is the cause of rapid changes (fading) of the signal parameters.

The signal at the output of the multi-beam transmission channel can be recorded as [6]: 


$$
\begin{aligned}
& y(t)=A_{p} \cos \left(2 f_{0} t+\Theta_{p}\right)+ \\
& +\sum_{i=1}^{n} z_{i} A_{0} \cos \left[\left(2 f_{0}+\Omega_{i}\right)\left(t-\tau_{i}\right)+\Theta_{i}\right],
\end{aligned}
$$

where $A_{p}$ is the regular component amplitude; $f_{0}$ is the average oscillation frequency; $t$ is the signal transmission time; $\Theta_{p}$ is the signal regular component phase; $n$ is the number of received rays of the useful signal at the receiver input; $z_{i}$ is the statistically independent random coefficient characterizing the effective transverse scattering; $A_{0}$ is the fluctuating amplitude; $\Omega_{i}$ is the fluctuating signal phase; $\tau_{i}$ is the delay time of the $i$-th beam during the passage of the path from the transmitter to the receiver of the radio; $\Theta_{i}$ is the statistically independent phase of the signal, which passed the $i$-th path.

Let's analyze ways to increase the noise immunity of military radio systems.

Known literature sources analysis [4, 6] allows to determine the main ways to increase the noise immunity of military radio systems, namely:

1. Frequency adaptation mechanisms involve the choice of the range of operating waves in which the effect of interference is minimal. This choice can be made at the planning stage of the radio communication system or at the interference protection operational management stage.

2. Energy adaptation mechanisms. They include:

- increasing the signal-to-noise ratio at the receiver input, which is achieved by increasing the transmitter power;

- the application of noise-tolerant principles of spacetime signal processing;

- the choice of modulation type and principles of signal demodulation;

- the application of noise-tolerant (correcting) codes; - the use of several physically separated communication channels;

- the use of channels with different feedback types.

Let's take a closer look at the main methods of increasing the noise immunity of military radio systems.

Signal-code constructions (SCC). Multi-position $M$-s signals are used to increase the data rate without expanding the occupied frequency band (increasing the bandwidth of the communication system). These signals are formed by using multi-position manipulation of the carrier oscillation in amplitude, frequency (phase) or in various combinations.

SCC can simultaneously solve the problem of increasing the reliability and speed of information transfer under strict restrictions on energy and frequency efficiency and solve most of the resulting contradictions. However, only harmonized SCC can increase the frequency or energy efficiency of radio communication systems without compromising other radiocommunication parameters.

Pre-coding methods use. Spatial multiplexing and diversity are controversially tied to the geometry and probabilistic characteristics of the channel matrix. It is theoretically proved $[6,7]$ that if the channel information is available only to the receiver, then there is a fundamental trade-off between multiplexing and diversity, in which one cannot increase and decrease the other. The situation changes if to assume that some parameters of the communication channel are known on the transmitting side and can be used to build the appropriate spatial signal-code structure.
In fact, such systems assume the presence of a feedback channel, and the procedure for forming the optimal signal-code structure in these conditions is called spatial pre-coding.

In the general case, pre-coding can be considered as one of the methods of spatio-temporal coding and as one of signal-code construction types.

It should be borne in mind that pre-coding requires feedback, because the pre-coding matrix is selected on the basis of a priori information about the state of the channel $[9,10]$.

Spatio-temporal signal processing method choice. Improving the efficiency of radio communication can be achieved through the use of various methods of spatio-temporal signal processing. It is theoretically proven that the bandwidth of radio communication devices using the methods of space-time signal processing can be increased. This is achieved by increasing the number of antenna channels on the transmitting side (provided that the number of receiving antennas is not less than the number of transmitting antennas), compared to traditional radio systems.

However, there is a controversy because of increasing the spectral efficiency that complicates the demodulator and reduces the noise immunity of the system. Therefore, it is necessary to choose a method of signal processing at the input of the radio receiver, which will increase the radio efficiency without compromising other characteristics and has a moderate computational complexity.

\section{Conclusions}

The research found that noise immunity studies of radio communication systems and facilities are limited to the research of the intentional interference effect on the noise immunity of radio communication systems and facilities, which are described by the normal Gaussian distribution law. However, intentional interferences are considered only of an additive nature, without taking into account the multiplicative interferences and interferences described by the non-Gaussian distribution law.

It is established that signal fading is usually described only by the law of Rayleigh, Rice and Nakagami. Moreover, in the known works, the authors calculate the fading effect in accordance with Rice's law to simplify the calculations. The noise immunity of radio channels is significantly impaired when the signal is faded, because it is not possible to use information about the actual values of the radio signals parameters. Thus, random changes in the parameters of the transmission channel are a multiplicative interference, which leads to distortion of the transmitted signals in the parameter random changes form.

It has also been found that the description of the only additive destructive component is incomplete, because multiplicative and additive destructive components are present at the radio receiver input.

The following ways to increase the noise immunity of radio communication systems and facilities are proposed:

- the use of operating frequency adaptive pseudo-random adjustment technologies, which are able to change the adjustment rate of the operating frequency, the initial polynomial filling, also the type and parameters of the useful signal in accordance with the electronic warfare intentional interference law;

- the use of multi-antenna radio communication devices with complex use of perspective methods of space-time 
signal processing, methods of pre-selection of operating frequencies and pre-coding methods;

- development and implementation of methods for assessing the channels state of military radio communication systems, which have minimal computational complexity and are able to increase the accuracy and reliability of the received assessment of the channel state;

- the use of noise-like signals with different expansion sequences that are able to regulate the autocorrelation properties of the useful signal;

- the use of hybrid information technologies that are able to increase energy and spectral efficiency of military radio communication systems (combination of known information technologies and mechanism combination to increase noise immunity in them);

- the use of artificial intelligence methods to increase the efficiency and reliability of decisions.

The research results will be useful in:

- increase mechanism definition of the radio communication devices noise immunity;

- recommendation substantiation for increasing the noise immunity of radio communication facilities;

- electronic situation analysis during hostilities (operations);

- while creating promising technologies to increase the radio communication noise immunity.

Areas of further research will focus on the development of a methodology for the operational management of intelligent military radio system interference protection.

\section{References}

1. Shyshatskyi, A. V., Bashkyrov, O. M., Kostyna, O. M. (2015) Rozvytok intehrovanykh system zviazku ta peredachi danykh dlia potreb Zbroinykh Syl. Ozbroiennia ta viiskova tekhnika, $1(5), 35-40$

2. Romanenko, I. O., Shyshatskyi, A. V., Zhyvotovskyi, R. M., Petruk, S. M. (2017). The concept of the organization of interaction of elements of military radio communication systems. Science and Technology of the Air Force of the Armed Forces of Ukraine, 1, 97-100.

3. Shevchenko, D. (2020). The set of indicators of the cyber security system in information and telecommunication networks of the Armed Forces of Ukraine. Modern Information Technologies in the Sphere of Security and Defence, 38 (2), 57-62. doi: http://doi.org/10.33099/2311-7249/2020-38-2-57-62

4. Sokolov, K. O., Hudyma, O. P., Tkachenko, V. A., Shyiatyi, O. B. (2015). Main directions of creation of IT infrastructure of the Ministry of Defense of Ukraine. Zbirnyk naukovykh prats Tsentru voienno-stratehichnykh doslidzhen, 3 (6), 26-30.

5. Kuvshynov, O. V. (2009). Adaptyvne upravlinnia zasobamy zavadozakhystu viiskovykh system radiozviazku. Zbirnyk naukovykh prats VIKNU, 17, 125-130.

6. Shaheen, E. M., Samir, M. (2013). Jamming Impact on the Performance of MIMO Space Time Block Coding Systems over Multi-path Fading Channel. REV Journal on Electronics and Communications, 3 (1-2), 68-72. doi: http://doi.org/10.21553/rev-jec.56

7. Abdukhalil, T., Yadgarova, N. (2018). Study of the Application of Noise Immunity in Radio Communication Systems for Special Courses. Bioprocess Engineering, 2 (2), 20-23. doi: http://doi.org/ 10.11648/j.be.20180202.11
8. Makarenko, S. I. (2017). Prospects and Problems of Development of Communication Networks of Special Purpose. Systems of Control, Communication and Security, 2, 18-68. Available at: http://sccs.intelgr.com/archive/2017-02/02-Makarenko.pdf

9. Khan, M. N., Jamil, M. (2016). Adaptive hybrid free space optical/radio frequency communication system. Telecommunication Systems, 65 (1), 117-126. doi: http://doi.org/10.1007/ s11235-016-0217-8

10. Adrat, M., Ascheid, G. (2015). Special Issue on Recent Innovations in Wireless Software-Defined Radio Systems. Journal of Signal Processing Systems, 78, 239-241. doi: http://doi.org/ 10.1007/s11265-014-0968-y

Andrii Shyshatskyi, PhD, Senior Researcher, Research Department of Electronic Warfare Development, Central Scientific Research Institute Armament and Military Equipment of the Armed Forces of Ukraine, Kyiv, Ukraine, ORCID: https://orcid.org/0000-00016731-6390,e-mail: ierikon13@gmail.com

Vitalii Hasan, Institute for Support of Troops (Forces) and Information Technologies, The National Defence University of Ukraine named after Ivan Cherniakhovskyi, Kyiv, Ukraine, ORCID: https:// orcid.org/0000-0002-2566-9144, e-mail: vitaliygasan@ukr.net

Mykola Kryvenko, Institute for Support of Troops (Forces) and Information Technologies, The National Defence University of Ukraine named after Ivan Cherniakhovskyi, Kyiv, Ukraine, ORCID: https:// orcid.org/0000-0002-3841-3164, e-mail: nvladkryvenko@gmail.com

Oleksandr Petrov, Institute for Support of Troops (Forces) and Information Technologies, The National Defence University of Ukraine named after Ivan Cherniakhovskyi, Kyiv, Ukraine, ORCID: https:// orcid.org/0000-0003-4369-7170, e-mail: avpetrov1975@gmail.com

Serhii Kravchuk, Institute for Support of Troops (Forces) and Information Technologies, The National Defence University of Ukraine named after Ivan Cherniakhovskyi, Kyiv, Ukraine, ORCID: http:// orcid.org/0000-0002-6042-154X, e-mail: sergeykravchuk@ukr.net

Yuriy Shidlovsky, Institute for Support of Troops (Forces) and Information Technologies, The National Defence University of Ukraine named after Ivan Cherniakhovskyi, Kyiv, Ukraine, ORCID: https:// orcid.org/0000-0003-1746-1703,e-mail: yurishidlovski@ukr.net

Andrii Opalak, Institute for Support of Troops (Forces) and Information Technologies, The National Defence University of Ukraine named after Ivan Cherniakhovskyi, Kyiv, Ukraine, ORCID: https:// orcid.org/0000-0002-5597-4182, e-mail: sapsan1100@ukr.net

Oleksandr Modlinskyi, Institute for Support of Troops (Forces) and Information Technologies, The National Defence University of Ukraine named after Ivan Cherniakhovskyi, Kyiv, Ukraine, ORCID: https:// orcid.org/0000-0002-8289-265X, e-mail: Gastello1799@gmail.com

Oleksii Kobylynskyi, Institute for Support of Troops (Forces) and Information Technologies, The National Defence University of Ukraine named after Ivan Cherniakhovskyi, Kyiv, Ukraine, ORCID: https:// orcid.org/0000-0003-1311-7120, e-mail: Gastello1799@gmail.com

Ihor Bezstrochnyi, Institute for Support of Troops (Forces) and Information Technologies, The National Defence University of Ukraine named after Ivan Cherniakhovskyi, Kyiv, Ukraine, ORCID: https:// orcid.org/0000-0002-8507-7095, e-mail: Gastello1799@gmail.com 